\title{
Humanizing Development: Taking Stock of Amartya Sen's Capability Approach
}

\author{
Pablo Garcés Velástegui ${ }^{\mathrm{a}}$
}

Date received: February 17, 2020. Date accepted: August 12, 2020.

http://doi.org/10.22201/iiec.20078951e.2020.203.69586

\begin{abstract}
Amartya Sen's capability approach redefined development in terms of people and their quality of life. Since development suggests the idea of positive change, it highlights what is worth changing, the desirable outcome and the desirable way to achieve it. This influential framework has succeeded in engaging different disciplines in constructive debate. There is a growing, and dispersed, literature adding and critiquing it. Hence, providing a current conceptual account of the approach, on its own terms, to assess its contribution to the project it undertakes, address its alleged shortcomings, and point to avenues to further the debate seems warranted. This is particularly timely given its 30 years of influence over public policy, as evidenced by the United Nations' Human Development Reports.
\end{abstract}

Key Words: human development; quality of life; functioning; capability; welfare; agency and conversion; welfare economics.

\section{Humanizando El DESARROLlo: un BALANCE DEl ENFoQUe de CAPACIDAdes de Amartya SEN}

Resumen. El enfoque de las capacidades de Amartya Sen redifinió el desarrollo en términos de la gente y su calidad de vida. Ya que sugiere la idea de un cambio positivo, dicho enfoque subraya lo que vale la pena cambiar y la deseabilidad tanto del resultado como la forma de lograrlo. También ha sido exitoso en involucrar diferentes disciplinas en un debate constructivo. Asimismo, hay una creciente y dispersa literatura aportando y criticándolo. Por lo tanto, proveer de un marco conceptual del enfoque en sus propios términos para evaluar su contribución al proyecto que pretende, abordar sus deficiencias y señalar rutas de posible discusión, parece sensato. Esto es particularmente adecuado dados los 30 años que ha influenciado la política pública, como lo evidencia los Reportes de Desarrollo Humano de las Naciones Unidas.

Palabras clave: desarrollo humano; calidad de vida; funcionamiento; capacidad; bienestar; agencia y conversión; economía del bienestar.

Clasificación JEL: I31; I38; O15.

\footnotetext{
${ }^{a}$ Instituto de Altos Estudios Nacionales y Pontificia Universidad Católica del Ecuador. Email addresses: pablo.garces@iaen.edu.ec and pfgarcesv@puce.edu.ec.
} 


\section{INTRODUCTION}

Development is not solely a descriptive concept but a normative one. It denotes change, but not any change. It conveys the idea of progress, advancement and betterment (Alkire and Deneulin, 2010). As such, it denotes "good change" (Chambers, 2004). Therefore, development ideas matter because they point out what matters. That is, they suggest what that change means, what ought to be changed and even how this change is to take place.

This means that there is no consensus on the meaning of the term. "Development" has had several definitions and been given various treatments, which have been related to human well-being, to a lesser or greater degree (Sen, 1988). However, different approaches and frameworks entail different foci about what matters but also different and important assumptions. If the latter do not obtain, the approach could be suspect. This realization becomes all the more relevant because studying "development" usually goes beyond an intellectual exercise, it seeks to have practical consequences. That is, to a great extent, development is about applied instrumental research (Mehta et al., 2006), which means that it affects (and seeks to do so) people's lives. After all, policy inspired by different approaches can well hit the target but miss the point. ${ }^{1}$

There are many fundamentally different ways of seeing the quality of living, and quite a few of them have some immediate plausibility. You could be well off, without being well. You could be well, without being able to lead the life you wanted. You could have got the life you wanted, without being happy. You could be happy, without having much freedom. You could have a good deal of freedom, without achieving much. We can go on (Sen, 1988, p. 1, emphasis in the original).

The capability approach, henceforth the CA, has become the most influential framework providing a notion of development. The offspring of Amartya Sen, it is a people-centered approach that focuses on human beings and their quality of life. At its heart lie two questions: "what are the lives that people are free to lead?" and "what lives have they chosen to lead?" By posing these

1 Apropos, Alkire (2010, p. 191) states: "The policies, practices, analyses, and measures that guide development institutions can be scrutinized to uncover which truly aim at human freedoms, and how true their aim might be. Much of Sen's development writings engage or draw on investigations of this form. By such inspection, the oversights of development theories might be uncovered and corrected. Such work is terribly salient, for lives are at stake. In development, Sen observes, 'a misconceived theory can kill'”. 
questions, and in answering them, it has fundamentally challenged previously dominant approaches to development.

This approach has proven influential within scholars and policy makers alike. There is a growing literature in a wide array of disciplines, mostly empirically oriented although conceptual as well, seeking to add to Sen's seminal work. The CA's contributions notwithstanding, it has also been subject to criticism. Whether in favor or against, much of the literature, has tended to evaluate it from a predetermined perspective. Providing a current conceptual account of the CA on its own terms so as to assess its contribution to the project it undertakes, address the alleged shortcomings and point to avenues to further the debate seems warranted. This is particularly so given its three decades influencing policy making the world over, as evidenced by the Human Development Reports issued by the United Nations Program for Development.

Consequently, in order to elaborate on the cA's contributions to the study of development and development policy, this article is structured in three sections, besides the introduction. In the first section, the $\mathrm{CA}$ is presented on its own terms, highlighting Sen's work and more recent contributions. On the basis of the previous discussion, the third section discusses the current conceptual scope and limitations of the approach, suggesting warranted avenues for future research. The final section concludes.

\section{HUMAN DEVELOPMENT}

The CA constitutes a conceptual framework to define development. As such, rather than being an explanatory theory suggesting how development can be achieved, it suggests a descriptive and normative account of how development can and should be understood. This section endeavors to present that account in its own terms, following Sen's work as well as what are arguably the most relevant additions to it from various disciplines.

The CA places humans, and their lives, at the center of development. It argues that people are the ends of development and that the latter ought to be assessed in terms of people's quality of life (Sen, 1999). Differing from measures of opulence, which focus on the means instead of on the ends of development, for the CA, income (or wealth) per capita is only instrumentally important; that is, it is only valuable to the extent it enables the achievement of intrinsically valuable aspects of life. These aspects and the things that can affect their attainment are conveyed in the approach's main concepts, namely functionings, capability, well-being, agency and conversion factors. 


\section{Evaluation space: functionings and capabilities}

The spaces where assessments of development should be performed are functionings and capabilities. Functionings are achieved "beings" and "doings" that people value and have reason to value (Sen, 1999). They are types of lives deemed valuable after reflection (Sen, 1993). An individual's achievements, therefore, can be regarded as the vector of their functionings (Sen, 1992). In this sense, they are constitutive to an individual's being (Sen, 1990) and living can be regarded as consisting of interrelated beings and doings (Sen, 1992).

The valued functionings may vary from elementary ones, such as being adequately nourished and being free from avoidable disease, to very complex activities or personal states, such as being able to take part in the life of the community and having self respect (Sen, 1999, p. 75).

Functionings, therefore, are personal and multidimensional. They are personal in that they reflect people's values and their idea of the good. Moreover, being types of life of people, they can be regarded as characteristics of people. This is a fundamental difference from other approaches such resource-based ones as these focus on the features of resources or commodities, not on people (Sen, 1988). Functionings are multidimensional because the incommensurability of human experience is recognized by their focus on a wide array of reflected upon valuable doings and beings, rejecting thereby the use of only one metric, as in conventional economistic approaches.

Capability can be regarded as the vector of the potential functionings that an individual can achieve (Sen, 1999). It denotes, someone's capability to function (Sen, 1992). It comprises all the possible functionings from which an individual can choose (e.g. having the choice: to be a mother, to pursue certain career regardless of gender, to earn the same wage for the same work regardless of any other factor, to elect and be elected, should these options be deemed valuable after reflection). Thus, it denotes the freedom one has to lead different valuable reflected upon lives (Sen, 1993). A valuable life is composed by both a person's doings and beings as well as the freedom to undertake them (Crocker and Robeyns, 2010). According to Sen (1999), development should be ideally considered in the space of capabilities. Therefore, he redefines development as freedom.

In this sense, Sen (1997) not only focuses on outcomes but on how they are reached. One can imagine two people, who value the same kind of live and enjoy the achievement of the same levels of doings and beings, but if these 
were imposed on one while the other had other options to choose from, it is clear that the latter enjoys a better quality of life. In this sense, focusing on outcomes only may be insufficient. This is what Sen (1997) calls "culmination outcomes", in contrast to "comprehensive outcomes", which take into consideration how those final outcomes came about, i.e. the process leading to them.

The capability approach focuses on people and their quality of life. It regards the improvement in people's lives as an expansion of their freedom. Therefore, from this perspective, development is about enlarging people's choices in all dimensions of life (Haq, 2004). Indeed, Mahbub ul Haq (2004, p. 31), one of the most relevant contributors to the approach, perhaps put it best: ${ }^{2}$

The human development paradigm covers all aspects of development -whether economic growth or international trade; budget deficits or fiscal policy; savings, investment or technology; basic social services or safety nets for the poor. No aspect of the development model falls outside its scope, but point of references remains the widening of people's choices and the enrichment of their lives. All aspects of life-economic, political or cultural- are viewed from that perspective. Economic growth therefore becomes only a subset of the human development paradigm.

Capability also underlines the CA's focus on human beings. It highlights human plurality in recognizing that there may be many doings and beings that are valuable after reflection, and many lives that can be legitimately led. As such, it recognizes the importance of command over resources or material opulence, but emphasizes that its value is instrumental, to the extent it enables people to reach intrinsically valuable objectives. Therefore, whether one assesses states of a person or a country, what matters is not the presence or extent of opulence but how that opulence is used (Sen, 1999). Moreover, capability is also a personal factor, since capabilities are bundles of functionings, which are constitutive of an individual's being. Additionally, it acknowledges that being able to choose from meaningful kinds of life is part of well-being. Similarly, as in the case of functionings, it stresses the multidimensional nature of human experience as well.

2 Although Haq talks about the human development approach, the contribution is pertinent since "[...] there is no consensus as to a conceptually clear distinction between human development and the capability approach, nor is it obvious that such a distinction is useful or required" (Alkire, 2010, p. 22, emphasis in the original). 
In this sense, although related to functionings, capability does not denote achievements but the freedom to achieve. "Freedom can be distinguished both from the means that sustain it and from the achievements that it sustains" (Sen, 1992, p. 86, emphasis in the original). Furthermore, even though they are distinct, freedoms are not independent from one another. Expansion in some may contribute to the expansion of others. Hence, freedom is the primary end and the principal means of development, also referred to as the constitutive and instrumental role of freedom in development, respectively (Sen, 1999).

Importantly, Sen (1988) emphasizes the difference between negative and positive freedoms, privileging the latter. Negative freedoms can be useful regarded as "being free from" (as in the libertarian tradition). That is, the focus is on the absence of constraints to the exercise of that freedom. In this sense, the attention is placed on the correctness of the process underlying and governing social behavior. An example can be the freedom to earn the same wage for the same job in the labor market regardless of sex, ethnicity, age or any other factor. As important as this is, if the interest is in the actual quality of life achieved by people, then such approach does not suffice. It is necessary to consider the positive freedom of being able to choose, i.e. "being free to". This focuses on the opportunity to achieve and, as such, is a relevant functioning in its own right (Sen, 1988). Thus, this aspect of freedom, paying attention to meaningful exercises of choice, can be included in the evaluation of functionings by "refined functionigs", which are functionings that take into consideration the availability of options (Sen, 1988). Consequently, both process and opportunity are aspects of freedom that need to be taken into account in development assessments (Sen, 1999). Nonetheless, the capability perspective is better equipped to account for the latter (Sen, 2005).

\section{Motivation: agency and well-being}

Regarding, well-being and agency, they can be considered as the categories approximating motivation. Well-being refers to an individual's quality of being (Sen, 1999). That is, it refers exclusively to her personal "wellness" (Sen, 1992) or welfare (Sen, 1993). This category denotes solely an individual's own states (e.g. being well nourished, being employed, enjoying leisure time, having selfesteem).

Agency, in turn, refers to what a person does or can do in order to pursue any of her goals and objectives, not just those that advance her own wellness. It is an evaluation of "what a person can do in line with his or her conception 
of the good" (Sen, 1985, p. 206). Hence, agency encompasses self-interest or self-regarding motivation (well-being) as well as other-regarding motivation (Crocker and Robeyns, 2010) (e.g. volunteering at a hospital, donating blood or organs, philanthropic activities).

Furthermore, agency denotes the extent to which people can control, influence and change the features of their environment in the pursuit of their goals. In this sense, agency itself has proven to be valuable. If functionings and capabilities were the only aspects of value, it would be irrelevant to assess how they come about and who decided over them.

From a public policy perspective, therefore, the stress is on regarding people as agents of change with the ability to shape their lives, to scrutinize their preferences and choices, to learn. That is, the cA rejects seen people merely as passive recipients of policy (Sen, 1999).

Importantly, there may be tension between agency and well-being goals. Whenever the pursuit of other-regarding objectives curtails self-regarding ones, there is a tradeoff. Following the examples above, donating bone narrow or a kidney to someone presumably entails a reduction in the donor's wellbeing while increasing their agency.

Additionally, functionings and capabilities can be manifested both in terms of agency and also in terms of well-being (see table 1). The relationship between functionings and well-being is perhaps intuitive since a person's welfare is dependent on their achievements, or the nature of their being. Whether basic functionings such as being literate or advanced ones like being self-confident, what a person does and is must be intrinsically important for the wellness of that person's being (Sen, 1992). When it comes to well-being capabilities, the relationship can be established in a twofold manner.

First, there is well-being freedom. This is the implication of capabilities being the set of all reasoned and valuable functionings. Since functionings are constitutive to a person's well-being and capability is the vector of meaningful functionings, then capability is a person's freedom to have well-being ${ }^{3}$ (Sen, 1992).

Second, achieved well-being can be regarded as dependent on the capability to function. This highlights the importance of choosing as intrinsically im-

3 As Sen (1992) points out, well-being capability can be assessed as desirable for instrumental as well as intrinsic reasons. Instrumentally, as argued in this section, it reflects the real opportunities people have to achieve well-being. In this sense, it shows the hand that people have been dealt. Intrinsically, it is worth highlighting the value that freedom has in and of itself. "A good society is also a society of freedom" (Sen, 1992, p. 41). 
portant for people's lives when there are real opportunities enabling reflective choice. The point is that, when assessing states, how a life style has occurred is itself relevant, not only that it has occurred. After all, a valuable achievement (say, being married) is likely to be more valuable if it is the product of reasoned choice (when the people involved have had meaningful options or suitors to choose from) than otherwise (as in the case of arranged marriages). Hence, well-being achievements are not independent of the process leading to them, as some capabilities may contribute directly to well-being (Sen, 1992).

Concerning the expression of functionings and capabilities in terms of agency, the relationships are expectedly similar. Apropos agency functionings, they are all the achievements that a person has reason to value (whether or not they are related to well-being). Being a superset of well-being, agency is also constitutive to a person's being. The goals a person seeks are the manifestations of their identity (Sen, 2007). This is so for self-regarding objectives as well as for other-regarding ones. Since the previous paragraph discussed the former, this one shall focus on the latter for analytic purposes, without reducing "agency" solely to altruistic motivations. In this, sense, non-self-interested achievements (e.g. men demonstrating in favor of the legalization of abortion, locals fighting for the rights of immigrants, going on a hunger strike for political prisoners, skipping one day of school every week to protest climate change) also constitute the nature of a person's being and, thus, they should enter the evaluation of a person's life.

Importantly, as can be gathered from the above, for the CA, agency (and well-being) functionings are about achievements, i.e. fulfilling objectives and values. This means successfully bringing about a desired goal. As Sen (1992, p. 56) has put it:

A person's agency achievement refers to the realization of goals and values she has reasons to pursue, whether or not they are connected with her own well-being. A person as an agent need not be guided only by her own well-being, and agency achievement refers to the person's success in the pursuit of the totality of her considered goals and objectives.

As in the case above, the relationship between agency and capabilities also points to the intrinsic value of choice. Agency freedom is about the real opportunity an individual has to obtain or reach the achievements they have reason to value and seek to realize. The relationship between the evaluative space (capability and functionings) and motivation (agency and well-being) is illustrated in table 1. 
Table 1. Combination of agency and well-being with functionings and capability

\begin{tabular}{llll} 
& & Motivations & \\
\cline { 3 - 4 } & & Well-being & Agency \\
\hline Evaluative space & Functionings & Well-being achievement & Agency achievement \\
& Capability & Well-being freedom & Agency freedom \\
\hline
\end{tabular}

Source: created by the author based on Crocker and Robeyns (2010).

Although distinguishable, agency and well-being are interdependent (Sen, 1992). On the one hand, well-being or the pursuit of self-regarding aims can be one of the goals that an individual qua agent values and has reason to value. On the other hand, other-regarding achievements can contribute to the agent's well-being. By the same token, the lack of achievement in otherregarding aims can be detrimental to well-being.

Finally, regarding agency and freedom, until 1992, Sen rejected a common association of freedom with direct control on agency-related grounds. "Freedom as control" was opposed due to its exclusive focus on people having the levers or power for the capabilities they enjoy, arguing that " $[\mathrm{m}]$ any freedoms take the form of our ability to get what we value and want, without the levers of control being directly operated by us" (Sen, 1992, p. 64). Accordingly, a differentiation was made between "realized agency success" and "instrumental agency success". The latter was concerned with those outcomes brought about by the agent themselves and, as such, conveyed the idea of freedom as control. The former, in turn, was broader and encompassed all outcomes, whether the agent was determinant in achieving them or not (Sen, 1992). Thereafter, however, that rejection and differentiation seems to have been dropped.

\section{Intervening elements: conversion factors}

Translating resources into functionings and capabilities, whether related to well-being or agency, is not direct. This process is mediated by conversion factors, which encompass internal as well as external characteristics that can influence the extent to which capabilities can be enjoyed and functionings obtained (see figure 1). Sen (1999) distinguishes the following conversion fac- 
Figure 1. lllustration of the CA's movement from means to ends

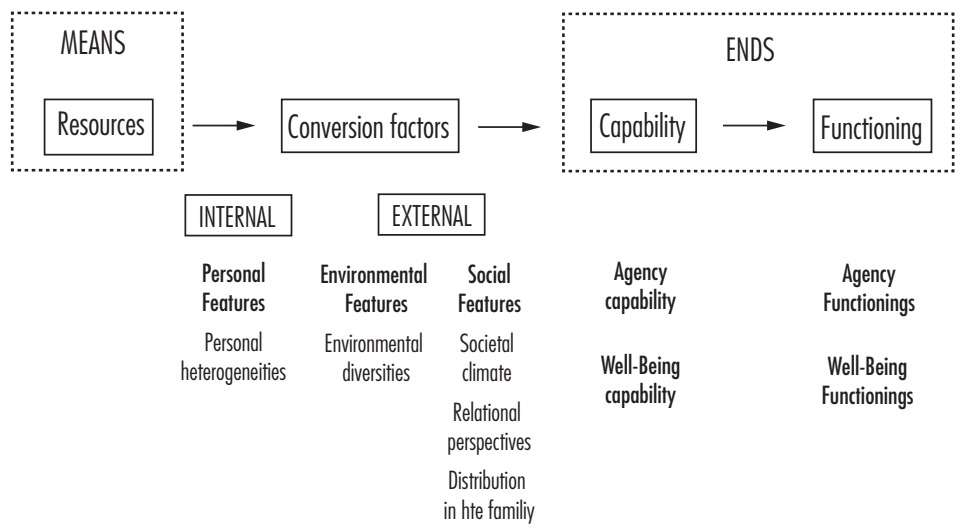

Fuente: created by the author based on Sen (1999) and (Crocker and Robeyns, 2010).

tors: i) personal heterogeneities; ii) environmental diversities; iii) variations in social climate; $i v$ ) differences in relational perspectives; $v$ ) distribution within the family. ${ }^{4}$

The previous discussion leads to diversity or the CA's recognition of human diversity, which occurs in at least two ways: the possible ends and the possible means to those ends. Sen (1992) has referred to the former as inter-end variation and to the latter as inter-individual variation. On the one hand, to the extent people have different meaningful and reasoned doings and beings, whether achieved or achievable, there is diversity in terms of the ends they pursue. This is increased by the CA's attention to agency. That is, the exercise of freedom to lead the lives people have reason to value entails that there is virtually an infinite number of legitimate lives people can lead.

On the other, even in the case of similar ends, different people in different contexts may require different quantities or qualities of resources to achieve them. In the case of a given end, the attention to specific personal as well as environmental and social characteristics highlights the fact that with similar resources, there can be considerable number of pathways to that end. This appears to be a tacit assumption in development policy since it often entails a standard intervention affecting certain individuals or groups in society and expecting them to meet a minimum score on an indicator considered desirable, despite their plurality. 
These variations are deeply interrelated. The actual freedom that an individual may have to pursue their valued ends depends on two factors: $i$ ) the ends that they have; and, ii) the power they have to convert resources or means into the achievement of those ends (Sen, 1992), which are their personal features (gender, class status, age, ethnicity, etc.) in the context in which they live (the country's capital, a religious family, a patriarchic society, etc.).

Again, for policy purposes, even in the case of a given end, although the challenge posed by inter-end variation is attenuated, the challenge posed by inter-individual variation remains. This goes against the rhetoric or belief conventionally assumed in welfare economic theory, that everyone is essentially similar, having the same maximal potentials (Sen, 1992) or, in other words, that "all men (humans) are created equal". For the CA, consequently, human diversity is a fundamental aspect of well-being. As such, it cannot be simplified and it ought to be factored in the analysis of development (policy).

\section{THE CA IN PRACTICE: SCOPE AND LIMITATIONS}

Sen's ca has gained much currency among academics and practitioners. Scholarly, it has been able to speak across disciplines, engaging a prolific debate. Furthermore, its adoption by the UN and the increasingly relevant Human Development Reports and Human Development Index (in any of its versions) speaks volumes of its influence for development practice. Nevertheless, because of its very nature, it has been subject to criticisms coming from different disciplines and addressing conceptual as well as empirical issues. Each aspect warrants independent discussion. Thus, this section is concerned with the former and presents the arguably main conceptual critiques raised by the literature, most of which have empirical import. Three themes are explored: selection and valuation, practical compromises and under-theorization.

\section{Selection and valuation}

In practice, and specially for policy and program analysis, it is necessary to define the ends of interest. Whether functionings or capability, the question as to what is of value demands an answer for practical purposes. This means that empirically selecting what are the important functionings and capabilities is unavoidable. As such, once it is accepted that the relevant space for evaluation is related to functionings and capabilities, given the multidimensionality embraced by both, the next is a discussion about which dimensions relevant 
to the quality of life are to be privileged. ${ }^{5}$ This entails real choice and process of evaluation from which there is no escape (Sen, 1992).

Not all functionings and capabilities are important, let alone equally relevant, just by virtue of being such. There are some that are of little interest while there are other rather significant, which are referred to as substantive freedoms (Sen, 1999). The CA's focus on functionings and capabilities does not mean that all types of achievements and freedoms are equally valuable, neither does it mean that all such objects have some value for a person, regardless of their effect on that person's life. The discrimination exercise to distinguish meaningful functionings and capabilities from negligible or trivial ones turns around the underlying concerns and values (Sen, 1992). Even in the case of the important ones, they would have to be weighted vis-a-vis each other.

According to the CA, these differences can be accounted for, to a certain extent. Sen (1999) suggests that weights can be attached to different freedoms, providing thereby a partial ranking or ordering that can prove useful. This is because freedom is inherently contested. The CA's goal, however, is not to provide a complete ordering of all states, as suggesting some ideal state to be reached, but to put in the locus of attention on those social aspects warranting improvement on which agreement can be found. Certainly, this leaves possible overall rankings as an issue of contention. Nevertheless, Sen (1999) argues that this does not undermine the approach. What would be damaging is neglecting relevant concerns because of omission of freedoms of those involved.

Because of the lack of selection and the absence of a definitive list the $\mathrm{CA}$ has been regarded as incomplete. The relevant literature recognizes the difficulties of this endeavor, however, there have been attempts to provide such list. One of the main contributors in this regard, and perhaps the best illustration, has been Nussbaum (2006), who proposes ten capabilities that ought to be included in the constitutions of all countries (and thus hers is referred to as "the capabilities [plural] approach"), namely: i) Life; ii) Bodily Health; iii) Bodily Integrity; iv) Senses, Imagination, and Thought; $v$ ) Emotions; vi) Practical Reason; vii) Affiliation; viii) Other Species; ix) Play; and, $x$ ) Control over One's Environment.

Nussbaum's contribution shares much with Sen's approach since it is consequentialist, ethically individualist and multidimensional. The evaluative

5 A related issue, particularly important for empirical exercises is that of the interrelations among dimensions. This is a relevant topic which would deserve an independent piece. Due to the conceptual nature of this discussion and the limits on its extension, therefore, it cannot be done justice here. For a discussion see Wagle (2005 and 2008). 
space is the quality of life people value and the aspects that have intrinsic importance. The focus is on the freedom and achievements of individuals. This decalogue encompasses a wide array of dimensions of human experience. However, Sen has not endorsed this list, or any list for that matter. The reason lies in the fact that Sen's CA rejects any general-purpose approach to the assessment of social states (Sen, 2004).

Sen's CA acknowledges the importance of selecting relevant dimensions and precisely because of this he has refused to endorse a particular final allpurpose list. As mentioned above, this approach privileges human diversity and free agency. This entails that selecting the relevant dimensions on which functionings and capability (or lack thereof) are to be assessed is a matter of public debate (Sen, 1999 and 2004). In fact, when it comes to attaching weights to different functionings and capabilities for social evaluation, the CA suggests such judgmental exercise has to be the result of a reasoned consensus or agreement based on open public deliberation and critical scrutiny. This is a social choice problem that demands a democratic process.

This suggestion applies to the three situations highlighting the CA's pluralism. First, as mentioned above, there are some functionings and capabilities that are more important than others, which requires weighting. Second, the importance of substantive freedom (the capability set) vis-a-vis actual achievement (the functioning vector) is also a matter of judgment, which requires weighting as well. Third, there is the relevance that processes and rules (process freedoms) can have vis-a-vis capabilities (opportunity or substantive freedoms). To recall, in all these cases, the matter at hand is human heterogeneity. In this sense, the capability perspective is not only "inescapably pluralist" (Sen, 1999, p. 76) but necessarily democratic.

Hence, from this perspective, no "complete ordering" of meaningful ends can be suggested. Indeed, well-being is an admittedly broad and partly opaque concept and trying to provide a ranking without room for ambiguity and incompleteness goes against the nature of these concepts and runs the risk of overprecision (Sen, 1992). Thus, depending on the exercise, different orderings in the prioritization of dimensions may apply and this is a call that only those affected by the evaluation can make. Any given list, comprising the doings and beings that people value and have reason to value (which are constitutive of their beings), ought to reflect those people's conception of the good and ought to be the product of those people's exercise of agency. Therefore, the shape that a list should take is a matter best left for the public sphere (Sen, 2004). In this sense, what has been criticized as underspecification is in fact taking free agency seriously. 


\section{Practical compromises}

The capability perspective advances a richer evaluative space and, by so doing, enlarges the informational base. This has implications for empirical applications. Capabilities themselves may present the greatest challenge, although not the only one. Nevertheless, this is attenuated, to an extent, by the ambitions and expectations of empirical exercises, which are adjusted to practical considerations. From fully-fletched applications to limited ones, the CA seems to be amenable to different strategies.

Conventional assessments of the options available within economics, whether achievements, substantive freedoms or both, place their real value on the best use that can be made of them, which coincides with the use that is actually made (under the assumption of a rational agent ${ }^{6}$ ). This is the intuition behind revealed preference approximations. Since choice is the only observable event, and an agent able of making optimal choices is assumed, the actual selection represents the best selection and, therefore, all alternatives can be evaluated in terms of the latter. In this sense, the use value of the opportunity lies solely on the value of one element, the chosen one, which is the best one. Consequently, following this tradition, focusing on the chosen functioning vector is the equivalent to focusing on the capability set. This approach was briefly mentioned above in terms of "refined functionings". An alternative, also mentioned above, is focusing on achieved functionings but also include choosing as one valuable functioning.

The value of a capability set, however, does not necessarily have to coincide with the value of the best or chosen element. From a capability perspective, the presence of valuable non-taken up options can also be of importance. In other words, simply having opportunities is itself valuable. This means moving beyond outcomes and paying attention to the process through which they are brought about and recognizing that it is important in and of itself. Hence, the relevance of choosing itself as a valuable functioning is highlighted. Accounting for these opportunities and others substantive freedoms, however, can prove rather challenging.

To recall, for evaluative purposes then the CA focuses either on realized functionings (i.e. the valued things a person is actually able to do or be or their lifestyles) or the capability set (i.e. the alternative combinations of doings and

6 Different characteristics have been attributed to the rational actor in economics. For this argument Sen (1999, p. 76) refers to two common assumptions: maximizing behavior and the absence of uncertainty. 
beings that are feasible for someone to achieve or their real opportunities). Some exercises admit evaluation on both. Sen (1999) distinguishes two levels of importance: the foundational and the practical one. At the foundational one, as has been argued throughout this paper, the capability perspective has proven its merits in contrast to the alternatives. This does not necessarily apply to the practical level. At this level, focusing exclusively on capabilities may not be warranted. Some capabilities may defy measurement more than others and attempts to capture them within a metric is likely to obscure them instead of illuminating them.

In light of the challenge posed by the evaluation of capabilities, Sen (1999) has recognized the strong need for pragmatism for use of available data for the purposes of empirical exercises, whether practical evaluation or policy analysis. In this sense, practical compromises are admitted in evaluative exercises, observing the pragmatic nature of practical reason. Thus, three alternative practical approaches to operationalize the capability perspective have been suggested, to wit, the direct, the supplementary and the indirect approach.

The direct approach is a fully-fletched way to include the concern with capabilities into the assessment of states. As such, it studies and compares directly vectors of functionings and capabilities. It has three variants: $i)$ total comparison; ii) partial ranking; and, iii) distinguished capability comparison. Total comparison involves the ranking or ordering of all vectors compared with each other in terms of poverty (or inequality or any other subject matter of interest). This is the most ambitious variant and, as such, judged to be the much too ambitious. Partial ranking, in turn, offers a less demanding alternative since it employs only a limited amount of functionings and capabilities to be used in interpersonal comparison. This raises the question of valuation and selection of the relevant vectors, which was addressed above. Finally, distinguished capability comparison refers to the selection of a specific capability of interest and the attention given exclusively to it. Longevity, employment, mobility, are some illustrations.

The supplementary approach advances a more conventional option for the assessment of states. It accepts the use of the income space for interpersonal comparisons but not exclusively. It supplements them by capability considerations, expanding thereby the informational base. This can be performed by focusing either on direct comparisons of functionings or on non-income instrumental variables that are expected to be related to capabilities. Some illustrations can be the presence of discrimination in voting rights, the access to basic services, etc. This means, using the distinguished capability comparison variant, described above, supplementarily. 
The indirect approach can be located somewhere in between the direct and the supplementary approaches. This alternative also follows the conventional focus on income variables but adjusts them by dint of non-income information that influences the determination of capabilities. In this sense, household income can be adjusted downward by the presence of disabilities or upward by the presence of a good bill of health. As such, this approach can be regarded as capability based equivalence scale. The advantages of this approach notwithstanding, it is not easier than the direct approach. Significant challenges such as the conversion rates that apply, the risk of confusing the unit of measurement as the with the cause of outcomes and the importance of recognizing the non-linear effect that income can have on people's quality of life ought to be adequately addressed (Sen, 1999).

Hence, this freedom-based perspective shows considerable catholicity and is not an all-or-nothing approach. The exact shape that the exercise may take depends both on the context and on the information available. Sen (1999, pp. 85 and 86) asserts: "The foundational proposition of the importance of capabilities can go with various strategies of actual evaluation involving practical compromises", and then continues "It is this combination of foundational analysis and pragmatic use that gives the capability approach its extensive reach".

\section{Under-theorization}

It has been argued that the CA suffers from being theoretically underspecified. Robeyns (2008, p. 94) has been emphatic:

The underspecified character of the capability approach requires that, before the capability approach can be applied for specific normative analyses, it has to be supplemented with additional theories. These theories include ontological theories about certain aspects of social and individual lives, and explanatory theories giving accounts of why states and processes are the way they are and how we should understand them. These supplementary theories also include normative accounts of the three conversion factors in the capability approach, and a normative theory of choice and personal responsibility.

Indeed, the capability approach is not a theory in the conventional sense of being able to provide explanation for social phenomena, let alone predictions. It does not explain poverty and neither does it explain development. Such theories would be helpful, however, they are arguably dependent on an adequate elaboration on the ontological and epistemological implications of the CA. The expectation that an explanatory theory can complement the CA, in 
the positivist sense, may be misplaced if the CA is found not to allow for such complementarity. Indeed, this might be case when capabilities and agency are studied, because of the counterfactual nature of the former (Comim, 2008) and the subjective nature of the latter (Alkire, 2007).

Additionally, further exploration of the evaluative space has proven useful. Indeed, the relevant literature has recently highlighted the relationship among achievements and deprivations. While functionings that contribute to the attainment of others are referred to as fertile functionings, deprivations that can worsen the likelihood of attainments are corrosive disadvantages (Wolff and De-Shalit, 2013). Whether capabilities or unfreedoms, functionings or deprivations, the implications for public policy are significant.

The CA's agency has also received some attention of late. Given that it resonates with the capability of political participation (in fact the latter could be an instance of the former), it has been argued that agency's value can be established in the same terms (Alkire, 2009). Hence, agency is regarded as being value in a threefold manner: i) intrinsically, ii) instrumentally; and, iii) constructively. Intrinsically, we have reason to value agency for its own sake, as a desirable end in and of itself. Agency enables people to be in control of their lives and destiny. Absent agency freedom, for instance, people with a certain quality of life could be "living as well-fed, well-clothed, and wellentertained vassals" (Drèze and Sen, 2002, p. 288). Hence, "[...] free agency itself a constitutive part of development" (Sen, 1999, p. 4). Instrumentally, agency is valuable due to the reflected upon positive ends that it can generate. It can contribute to the achievement of functionings and the enjoyment of capabilities. It is people's agency that allows people pull themselves by the bootstraps. Also, as in the case of capabilities, agency is not only an end but also an important means towards similar ends. Free agency " $[. .$.$] contribu-$ tes to the strengthening of free agencies of other kinds" (Sen, 1999, p. 4). Constructively, agency allows people to reflect upon, select and mold their values. Reasoning, therefore, is inherent to agency ${ }^{7}$ (Garcés, 2019a). Because of this, agency enables critical thinking and analytical (self) evaluation, for example in the case of weighting capabilities and other values (Sen, 1999; Crocker and Robeyns, 2010), as in the selection of relevant functionings or capabilities, a problem for which there is no escape (Sen, 1992).

Similarly, recent contributions to the CA have also addressed conversion factors. These can be constraints as Sen (1999) has argued. But recently

Consequently, contrasting with the dominant rational agent, the CA's agent has been recently described as a reasoning agent (Garcés, 2019a). 
their role as enablements for agency and the enjoyment of capabilities or the achievement of functionings has also been persuasively been pointed out (Hvinden and Halvorsen, 2018). To a certain extent, this may also entail the heuristic apprehension of perceptions and subjectivities since different conversion factors may mean different things to different people.

Likewise, the important issue of the nature of the entities of interest (ontology) has not been given due attention. This seems to be particularly the case of the significant issue of the agent-structure dynamic. These are related issues and are related to the philosophy of science. Little, if anything, has been said about the $\mathrm{CA}$ and its implications for the latter or vice versa. What has been said has dealt mostly with ontology. Interestingly, however, within the CA's camp, instead of exploring what the its ontology is, the discussion has been mainly been to show what it is not. In this sense, it has been convincingly argued that the CA does not spouse an individualist ontology (and methodological individualism in general) (Robeyns, 2008 and 2017). This has been an important contribution, as it has shed light on a misconception regarding the $\mathrm{CA}^{\prime}$ 's focus on individuals as the ultimate ethical unit of analysis.

There have been incipient efforts to address the ontological question. Martins (2007 and 2009), for example, based on a critical realist analysis, suggests that the CA advances a social ontology. This proposal is certainly provocative as provides an alternative to positivism. It, however, still needs to be thoroughly elaborated in order assess its advantages and disadvantages. Particularly problematic are the ontological commitment that critical realism makes, that the CA does not. Another alternative is pragmatism, which has been very loosely associated to the CA (Zimmermann, 2006), although nothing has been said about this at the level of the philosophy of science, despite it showing promise (Garcés, 2019b). Hence, much more work is necessary in order to provide an account that accommodates the capability approach's proposal. Since the CA has indeed challenged the convention in economics and development, such efforts may require challenging those of the philosophy of science as well. Taking on that enterprise is important intrinsically and instrumentally. On the one hand, in and of itself it is relevant to clarify the underpinnings of the approach. On the other hand, that clarification can guide better empirical exercises.

\section{CONCLUSIONS}

Development is a value-laden notion. It not only suggests the idea of change but of positive change. Theories, approaches and ideas about development 
matter because they point to what matters. At their most basic, they point to that which is worth changing and indicate the direction of change. That being so, these notions entail not solely abstract undertakings and intellectual endeavors but intentional attempts to influence people and induce that change. This is evident in the translation of development research to practice by way of development policy. The relevance of discussing development, thus, can hardly be overstated as people's lives are at stake.

The CA focuses on people and those aspects of life that make it worthwhile. Development's purpose is the enlargement of people's freedoms and encompasses every dimension of an individual's life (Haq, 1995). The evaluative space are functionings and capabilities. While the former denotes the achieved doings and beings that one values and has reason to value, which are constitutive to a person's being, the latter refers to the possible combinations of functionings. They establish the move beyond economic variables and single figures (and dimensions) and into multidimensionality. Hence, public policy ought to seek to enlarge people's substantive freedoms and achievements. To reiterate, these are not only the ends of policy but some of its more important means.

The motivational aspects of the CA are well-being and agency. Whereas well-being indicates self-interest, agency encompasses the totality of one's motivations, self-regarding as well as other-regarding. As such, agency underlines human diversity as people can have multiple goals that they value and have reason to value. Thus, both functionings and capabilities can be evidenced in either motivational aspect. Further, although these aspects are interdependent, they are also distinct and move in the same and in opposite directions.

Finally, the translation from resources or entitlements into functionings and capabilities is far from direct. It is mediated by "conversion factors", which further highlight human diversity. These are personal as well as contextual (social and environmental) attributes that intervene in that translation. Different people in different contexts may require different quantities or qualities of resources to achieve similar outcomes. Therefore, whether freedoms and achievements are to be assessed in terms of agency or well-being, public policies and administrations would do well to factor in human plurality into their designs and evaluation. Their effectiveness and legitimacy can thereby be enhanced, benefitting all stakeholders.

Its advantages notwithstanding, it has also been subjected to criticisms. In conceptual terms, the focus of this article, arguably the most significant ones can be grouped in three themes: selection and valuation; practical compromises; and, under-theorization. Regarding the selection of freedom or 
achievements, Sen has been emphatic in pointing out that the expectation of a definitive list is antithetical to the approach's notion of agency. Accordingly, the CA stresses that the lists depend on the purposes of the exercise and of the people involved. It is people, as agents in charge of their destinies, who must decide on their priorities.

Concerning how amenable the CA is for empirical exercises, Sen has recognized that the approach places a tall order on information. Therefore, it has admitted that certain exercises may require practical compromises and, for example, focus on functionings, the observed state, since capabilities entail counterfactual that might be overly taxing to capture.

Apropos its theoretical shortcomings, while explanatory theories seem outside its scope, the CA has still to address some normative and ontological issues. The research agenda has traditionally shown an empirical orientation in detriment to these themes. The recent and certainly rewarding efforts dedicated to multidimensional poverty indicators is but one example of this.

Each of these three areas constitute promising avenues for further research: exploring the mechanisms for selecting and agreeing upon the relevant dimensions, incorporating alternative tools in policy analysts' toolbox for empirical applications of the CA (e.g. Garcés, 2019c and 2020); exploring the implications of its notion of agency; and fleshing out the philosophical (metaphysical) commitments made by the CA can contribute to better conduct development research and practice.

\section{REFERENCES}

Alkire, S. (2007), "Measuring agency: Issues and possibilities", Indian Journal of Human Development, vol. 1, no. 1, DOI <https:/doi.org/10.1177/ 0973703020070110>

(2009), "Concepts and measures of agency", in K. Basu and R. Kanbur (eds.), Arguments for a better world, essays in honor of Amartya Sen (vol. I), Oxford University Press.

(2010), "Human development: Definitions, critiques and related concepts", Human Development Research Paper 2010/0.1, Oxford, Oxford Poverty \& Human Development Initiative (OPHI).

Alkire, S. and Deneulin, S. (2010), "The human development and capability approach", in S. Deneulin and L. Shahani (eds.), An introduction to the human development and capability approach, London, Earthscan. 
Chambers, R. (2004), "Ideas for Development", IDS Working Paper 238, Sussex.

Comim, F. (2008), "Measuring capabilities", in S. Alkire, F. Comim and M. Qizilibash (eds.), The capability approach in human development: Concepts, applications and measurement, England, Cambridge University Press.

Crocker, D. and Robeyns, I. (2010), "Capability and agency", in C. Morris (ed.), Amartya Sen, England, Cambridge University Press.

Drèze, J. and Sen, A. (2002), India; Development and Participation, Oxford University Press.

Garcés, P. (2019a), "The reasoning agent: Agency in the capability approach and some implications for development research and practice", Iberoamerican Journal of Development Studies (forthcoming), DOI <https://doi. org/10.26754/ojs_ried/ijds.491>

(2019b), "Form follows function in evidence-based public policy: the pragmatist alternative to the positivist orthodoxy", Iberoamerican Journal of Development Studies, vol. 8, no. 2, DOI <https://doi.org/10.26754/ ojs_ried/ijds.310>

(2019c), "Of ends and means: Development policy assessment with human development and multiple causality", Desarrollo \& Sociedad, 83, DOI <https://doi.org/10.13043/dys.83.10>

(2020), "Using the capability approach and fuzzy set qualitative comparative analysis in development policy evaluation", Journal of Comparative Policy Analysis, DOI <https://doi.org/10.1080/13876988.2019.1699277> Haq, M. (1995), "The human development paradigm", in M. Haq (ed.), Reflections on Human Development, Oxford University Press.

(2004), "The human development paradigm" in S. Fukuda-Parr and K. Shiva (eds), Readings in human development, Oxford University Press.

Hvinden, B. and Halvorsen, R. (2018), "Mediating agency and structure in sociology: What role for conversion factors?", Critical Sociology, vol. 44, no. 6, DOI <https://doi.org/10.1177/0896920516684541>

Martins, N. (2007), "Ethics, ontology and capabilities", Review of Political Economy, vol. 19, no. 1, DOI <https://doi.org/10.1080/09538250601080768> (2009), "Rules, social ontology and collective identity", Journal for the Theory of Social Behavior, vol. 39, no. 3, DOI <https://doi.org/10.1111 /j.1468-5914.2009.00406.x>

Mehta, L., Haug, R. and Haddad, L. (2006), "Reinventing development research", Forum for Development Studies, vol. 33, no. 1, DOI <https://doi.or g/10.1080/08039410.2006.9666339> 
Nussbaum, M. (2006), Women and human development: the capabilities approach, England, Cambridge University Press.

Robeyns, I. (2008), "Sen's capability approach and feminist concerns", in S. Alkire, F. Comim and M. Qizilibash (eds.), The capability approach in human development: Concepts, applications and measurement, England, Cambridge University Press.

(2017), Well-being, freedom and social justice: The capability approach re-examined, Open Book Publishers.

Sen, A. (1985), "Well-being, agency and freedom. The Dewey lectures 1984", Journal of Philosophy, 82, DOI <10.2307/2026184>

(1988), "The concept of development", in H. Chenery and T. Srinivasan (eds.), Handbook of Development Economics, Elsevier Science Publishers. (1990), "Development as capability expansion", in K. Griffin and J. Knight (eds.), Human development and the international development strategy for the 1990, Macmillan.

(1992), Inequality Reexamined, Oxford University Press.

(1993), "Capability and well-being", in M. Nussbaum and A. Sen (eds.), The quality of life, Oxford, Clarendon Press.

(1997), "Maximization and the art of choice", Econometrica, vol. 65, núm. 4, DOI <10.2307/2171939>

(1999), Development as freedom, Oxford University Press.

(2004), "Capabilities, lists, and public reason: Continuing the conversation", Feminist Economics, vol. 10, no. 3, DOI <https://doi.org/10.108 $0 / 1354570042000315163>$

(2005), "Human Rights and capabilities", Journal of Human Development, vol. 6, no. 2, DoI <https://doi.org/10.1080/14649880500120491> (2007), Identity and violence: The illusion of destiny, London, Penguin. (2009), The idea of justice, Harvard University Press.

Wagle, U. (2005), "Multidimensional poverty measurement with economic social well-being, capability and social inclusion: A case from Kathmandu, Nepal", Journal of Human Development, vol. 6, no. 3, DOI <https://doi. org/10.1080/14649880500287621>

(2008), Multidimensional poverty measurement: Concepts and applications, Springer.

Wolff, J. and De-Shalit, A. (2013), Disadvantage, Oxford University Press.

Zimmermann, B. (2006), "Pragmatism and the capability approach: Challenges in social theory and empirical research", European Journal of Social Theory, vol. 9, no. 4, DOI <https://doi.org/10.1177/1368431006073014> 